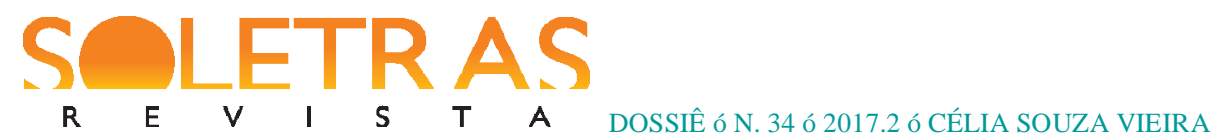

\title{
José Maria da Cunha Seixas (1836-1895), filósofo e crítico literário
}

\author{
Célia Souza Vieira ${ }^{1}$
}

\begin{abstract}
Resumo: Em Portugal, um dos pensadores menos estudados, do ponto de vista da crítica literária, na difícil conjugação entre a tradição de uma mentalidade idealista e a emergência do pensamento positivista, é José Maria da Cunha Seixas (1836-1895), filósofo e advogado que se distinguiu, ao longo dos vários volumes ensaísticos publicados nas décadas de 70 e de 80 , não propriamente por uma refutação peremptória do Positivismo, embora o seu itinerário de reflexão esteja associado ao combate antimaterialista, mas por uma tentativa de harmonização dos seus princípios com as correntes idealistas alemãs, nomeadamente com o krausismo, de que o seu sistema filosófico deriva e diverge. Neste artigo, procuraremos sintetizar a sua perspectiva, no contexto do amplo debate da crítica literária naturalista e antinaturalista portuguesa dos Oitocentos, utilizando como fontes de pesquisa as obras poéticas e filosóficas do autor depositadas nos fundos bibliográficos da Biblioteca Nacional de Portugal, da Biblioteca Pública Municipal do Porto e da Biblioteca da Faculdade de Letras da Universidade do Porto.
\end{abstract}

Palavras-chave: Cunha Seixas. Naturalismo.Pantiteísmo.Críticaliterária.Literatura.

\section{Introdução}

Um dos fatos que avulta como mais marcante no fenômeno de gestação e de afirmação da estética romanesca naturalista, no espaço ibérico e ibero-americano, é aquele que nos remete para a interdisciplinaridade entre o texto literário e os seus arquitextos filosóficos, ideológicos e científicos. Nesse sentido, parece emergir como tendência da literatura e da filosofia ibéricas o pendor para certo ecletismo que reduz a oposição entre cientismo e filosofismo e que tende para a busca, acima do plano concreto da exigência de modernização científica, de um sincretismo, de uma síntese que seria, como sugeria Antero de Quental ñum espiritualismo idealista, enxertado, para florir e frutificar, no tronco robusto do materialismoò(QUENTAL, 1890, p. 302). É nesse clima, por exemplo, que, em Portugal, fora gerada, já na década de 50, a Escola do Porto (BRITO, 1982, 1987), enquanto assunção de ñespecíficas coordenadas ï o livre arbítrio, a crítica da religião, a análise do cristianismo, a fulgência de um racionalismo deísta, a fundamentação de uma filosofia [é ], a cedência aos apelos messiânicos e proféticos, e o compromisso no pragmatismo das reformas políticas e sociaisò (GOMES, 2002, p. 47). É também sobre a vontade de fazer convergir, num único

\footnotetext{
${ }^{1}$ Célia Vieira é professora universitária no ISMAI (Instituto Universitário da Maia) e investigadora do Centro Investigação em Artes e Comunicação (CIAC). Especializou-se em literatura comparada, com a tese de doutoramento Teoria do romance naturalista ibérico e sua orientação francesa.cvieira@ismai.pt
} 
sistema, o cientismo, a religiosidade, a reforma individual e social, que o Krausismo se expande, em Espanha, enformando de modo indelével as gerações reveladas após 1870. Com efeito, vindo inscrever-se num processo de revisão da Filosofia do Direito, sob a influência de Proudhon e dos discípulos de Krause, a batalha naturalista reacendeu, ao mesmo tempo, o debate sobre os limites da ação humana e estimulou diversas tentativas de refundição de um novo Idealismo.

É neste contexto que se situa José Maria da Cunha Seixas (1836-1895), filósofo e advogado português que consagrou a sua vida intelectual ao aperfeiçoamento do sistema filosófico que criou, o Pantiteísmo.

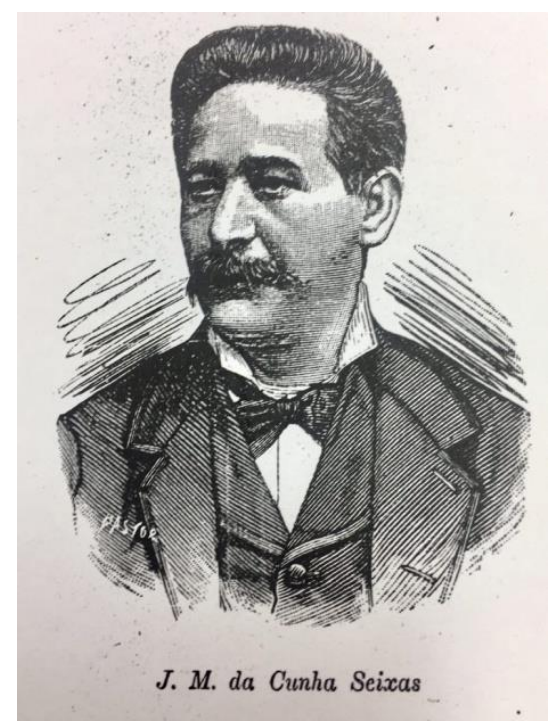

Fig. 1:J. M. da Cunha Seixas.

Fonte: Seixas, Cunha, J. M. (1897). Principios geraes de philosophia, Lisboa, Imprensa Lucas. Exemplar da Biblioteca Central da Faculdade de Letras da Universidade do Porto.

Esse pensamento, explanado nas obras A Phenix ou a Immortalidade da Alma Humana (Lisboa, 1870), Princípios Gerais da Filosofia da História (Lisboa, 1878, $2^{\text {a }}$ ed. aum., 1897), Galeria de Sciencias Contemporaneas (Porto, 1879), O Pantitheismo da Arte: cantos e poesias(Lisboa, 1883), Ensaios de critica philosophica ou exposição do estado actual da philosophia (Lisboa, 1883), Estudos de Literatura e de Filosofiasegundo o systema pantitheista (Lisboa, 1884), deveria ser objeto de uma publicação colossal com 1072 páginas, que chegou a ser impressa, mas que se terá perdido por um acidente da gráfica e de que apenas foi publicada postumamente uma parte, os Principios Geraes de Philosophia, em 1897. A rejeição a que o votou a intelligentzia positivista foi, em grande medida, provocada pelo seu confronto com Teófilo Braga, em cujas obras Cunha Seixas frequentemente apontou 
incongruências e juízos simplistas. Cada obra sua constituía ñum novo escândalo, um novo crimeò, porque, como afirma no prólogo aos Estudos de Filosofia e de Literatura (1884), pensar por conta própria e ñreagir contra a esphera do materialismo, que ahi vae, alliado a uma ignorancia tanto mais ousada como inconsciente, é uma temeridadeò (SEIXAS, 1884, p. XIV). Depois de ser preterido no concurso para a cátedra de estética em favor de Consiglieri Pedroso, discípulo de Teófilo Braga, acabou por se resignar a uma carreira como advogado e como professor do liceu em Lisboa, que pouco tempo lhe deixava para o colossal trabalho de síntese filosófica que se propunha realizar. Em 1883, quando publica O Pantitheísmo na Arte, confessa, no prólogo, que se sente desanimar, sem tempo para terminar o seu vastíssimo estudo, num ñpaiz ignorante e pouco animadorò. Só marginalmente a sua craveira intelectual foi reconhecida, tendo integrado várias Associações culturais, entre as quais, o Instituto de Coimbra, a Sociedade de Geografia de Lisboa, a Associação dos Jornalistas e Escritores Portugueses, a Sociedade Econômica Matritense, o Retiro Litterario Portuguez (Brasil), a Academia Mont-real de Toulouse, e tendo mantido em permanência a sua atividade como colaborador em vários periódicos.

Ao refletir sobre a indiferença que os intelectuais seus contemporâneos manifestaram relativamente ao vasto sistema filosófico que criou, J. M. da Cunha Seixas sonhava com uma geração futura que viesse a fazer-lhe justiça e a dar atenção ña um trabalho colossal, que não póde dormir no pó das livrariasò (SEIXAS, 1884, XV). Se efetivamente o século XX veio remir do silêncio a sua criação filosófica, já como crítico literário e escritor a sua imagem não foi ainda resgatada para que se reconheça a perspectiva original que adotou durante o intenso período da batalha naturalista. Não é nosso propósito expor com rigor o sistema filosófico de Cunha Seixas, que tem, aliás, chamado a atenção, pela sua originalidade na História da Filosofia Portuguesa no século XIX, de vários estudiosos (RIBEIRO, 1959; BORGES, 1995; TEIXEIRA, 1995; GOMES, 2006), uma doutrina nova a que deu o nome de Pantitheismo (termo que significa ñDeus em tudoò) e que ñreconhece Deus, como centro de todas as cousas e nâllas manifestado: declara elementos universaes das cousas as leis logicas da razão, tidas como condicções das realidades, da existencia e da possibilidade, sendo elementos particulares os fornecidos pela experienciaò (SEIXAS, 1883, VII). ${ }^{2}$ Gostaríamos somente

\footnotetext{
${ }^{2} \mathrm{Ou}$, em verso, e no mesmo volume: ñÉ meu credo, que Deus é o verbo eterno,/ De que os tempos não sabem dar-nos era:/ Que em mundos sobre mundos escrevêra/ Os codigos do seu poder superno./ Raios de luz ingente foram penna,/ Com que deu traços pôaa tamanha scena:/ Cada sêr é uma lettra, que sahíra/ Dâesses raios de luz, que não expiraò(SEIXAS, 1883, XIII).
} 
desalientar a sua faceta menos conhecida como crítico literário, tendo em conta que os pontos de contato que o sistema filosófico criado por Cunha Seixas apresenta com o Krausismo, de que deriva e diverge, o conduzem, a partir da articulação entre o conhecimento científico e o ñespiritualismoò, a uma perspectiva particular sobre a noção de realismo e de naturalismo, num contexto histórico-literário, a década de 80 , que corresponde a um momento em que os opositores de um naturalismo triunfante encontram mais dificuldades em renovar os argumentos para uma impugnação crítica, já que, na prática e na teoria, na oferta e na procura dos produtos romanescos, o naturalismo alcançava vantagem.

\title{
Do sensível ao ñultrassensívelò
}

\author{
A LUZ \\ Todo o sabio, que se presa, \\ É sempre naturalista: \\ No seu credo é um artista, \\ Sem passar da naturesa. \\ Mas o sabio, que regista \\ Aquillo só, que lhe peza, \\ E não vê maior alteza, \\ Mostra ter só curta vista. \\ Não há milagres no mundo; \\ Mas há maior maravilha, \\ Se o teu estudo é profundo. \\ Tu, que vês sómente a filha, \\ Busca o pae: é tudo oriundo \\ Nôıma luz, que sempre brilha. \\ (In:O Pantitheismo na Arte:cantos e \\ poesias, 1883, p. 17).
}

O poema acima transcrito, retirado do curioso volume poético e de síntese filosófica O Pantitheismo na Arte: cantos e poesias, de 1883, resume a convicção de que a ciência humana não poderia restringir o seu campo de conhecimento ao mundo sensível e de que o conhecimento experimental, sendo louvável, deve admitir uma outra dimensão da realidade cuja existência não poderia negar. Para J. M. da Cunha Seixas,

[...] a pobre sciencia humana apenas divisa longinquos vislumbres do organismo universal, divisando porém sob o phenomenalismo do sensivel umas realidades mais vivas, mais perfeitas e mais duradouras. [...] Há pois dois mundos: um sensivel e outro ultra-sensivel, ambos reaes e ambos com 


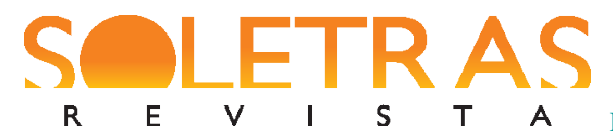

DOSSIÊ ï N. 34 ï 2017.2 ï CÉLIA SOUZA VIEIRA

direito á sciencia. Se aquelle é de mais facil ingresso que este, se pouco podemos perceber da profunda realidade, que está encoberta sob estas fórmas, que mais ou menos phantasmagoricamente nos gyram ante os sentidos, não é forçoso, que a sciencia, sempre pobre, expulse dos seus quadros uma realidade, que se não póde negar (SEIXAS, 1884, p. XVI).

Com efeito, para o filósofo, ñdesprender dos dados experimentados tudo o que sobrenada acima da brutalidade mechanica já seria um bom serviço da scienciaò (SEIXAS, 1884, XIV), porém, deveria ela ir mais longe e integrar o Positivismo no Espiritualismo, num sistema harmônico, que reconhece a existência de ñdois mundosò, que aceitando a ñpobresa dos nossos meios de conhecimento, não despresa um só: usa de todos os methodosò, que ñnão trunca dogmaticamente os meios de conhecermosò, que é ñpois, mais real, porque é mais verdadeiro e mais adequado aos sentimentos universaes de sciencia, de moral, de religiosidade, que distinguem a humanidadeò (SEIXAS, 1884, p. XIV-XV). Nesta perspectiva, então, seria fundamental reconhecer a indissolúvel aliança, não só entre ciência e espiritualismo, como entre ciência e filosofia. Integrando um escol de autores de formação humanística, como Silvestre Pinheiro Ferreira, Domingos Tarrozo, Silvestre de Morais ou Leonardo Coimbra, que procuraram, na tradição filosófica portuguesa (GOMES, 2005), reduzir a oposição entre cientismo e filosofismo, para este pensador, a ñphilosophia é a coroa das sciencias. Sem um estudo cabal dos principios geraes e leis de todas as sciencias não há philosopho possivelò. Seria ñnecessario concatenarem-se todas as leis sob principios geraes e para esse fim irem-se formando syntheses especiaes, que sob principios superiores formem um conjunto unitario e harmonicoò (SEIXAS, 1884, XXI),tarefa que compreende ser inglória, num país onde o Positivismo constitui a filosofia suficiente: aqui, como lamenta, T̃á apenas algum movimento positivista, porque, sendo o positivismo uma doutrina muito simples, muito dogmatica e muito arbitrariaò, constitui uma ñphantasmagorica certeza, que não passa de uma illusãoò. Ora, ñQuem tiver esphera mais larga, como a tem os sabios da Alemanha, olhará dôlto essa doutrinaò (SEIXAS, 1883, p. IX, X). Não há nem nunca houve, para Cunha Seixas, ñuma sociologia theologica, outra metaphysica e outra positiva. As distincções, que se figuram, são falsas. [...] Há uma única sciencia. Não há sciencia theologica, nem sciencia metaphysica, nem sciencia positiva. Há principios superiores e universaes, e há factos experimentaesò(SEIXAS, 1883, p. XL).

Exemplar no empenho em fornecer um sistema filosófico que ñabranja o movimento actual sem se abdicarem os dogmas espiritualistasò (SEIXAS, 1879, p. VII) é o volume 
Galeria de Ciências Contemporâneas, redigido com vista a provar a necessidade de reestruturar o Curso Superior de Letras, reformulando os seus curricula e o próprio programa das cadeiras lecionadas, de modo a refletir o atual movimento científico e filosófico. Assim, e embora, no prólogo, declare que, ao apresentar o último estado de cada uma das ciências de que trata, pretenda expor um ponto de vista ñespiritualista e de combate contra o materialismoò, o conteúdo do volume documenta bem a influência da filosofia ñ́krauseanaòna apologia de uma coordenação T̃harmonicaò do universo, enunciada em afirmações como esta: ñSer, manifestação e harmonia, são as leis universaes, applicaveis ao universo, ás sciencias, ao homem, finalmente a tudo o que possa pensarò (SEIXAS, 1879, p. 151). Assim, a sua concepção sobre a ciência do belo, longamente exposta entre os capítulos XVIII a XXI, será também ela marcada pelo pendor eclético do seu pensamento.

Depois de fazer uma revisão liminar dos juízos de Kant, Fichte, Schelling, Hegel, Krause, Jouffroy (Cours dôEsthetique, 1842), Victor Cousin (Du vrai, du beau et du bien, 1860), Lamennais (De lôArt et du Beau, 1865), Leveque (La Science du Beau, 1861), Vico, Gioberti (Essai sur le Beau, 1843), Taine (De lâdéal dans lôtrt, 1867, Philosophie de lôtrt, 1872), Proudhon (Du Principe de lôArt et de sa Destination Sociale, 1875), nem sempre lidos nos seus originais, mas frequentemente apreendidos em versões francesas ou através de obras de síntese como a de L. Dumont, Theorie Scientifique de la Sensibilité, a de T. Desdouits, La Philosophie de Kant (1876) ou a de Gauckler, Le Beau et son Histoire (1873), expõe uma concepção estética fundada na primazia do infinito na arte edefine, então, o belo como um conceito para o qual não concorre ño agradavel, nem o bom, nem a imitação da naturezaò, mas que se impõe à sensibilidade por um ñcaracter superior de universalidade e impersonalidadeò (SEIXAS, 1879, p. 150). José Maria da Cunha Seixas desenvolve uma teoria estética platônica pela qual o belo é composto por uma vertente variável e transitória, sujeita a circunstâncias históricas, geográficas, culturais e biográficas, e que corresponde à forma; e por uma vertente essencial e imutável, que corresponde a um arquétipo de belo comum e subjacente a qualquer manifestação de beleza. As leis krausistas de ñnidade, variedade e harmoniaò encontrariam, desse modo, plena aplicação, numa teoria estética, que, pelo lado infinito e divino, concebe o belo como participante num sistema universal, uno e orgânico, e, pelo lado finito, o dota de uma individualidade própria: assim, a 


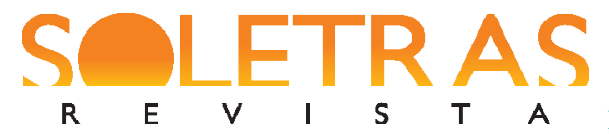

DOSSIÊ ï N. 34 ï 2017.2 ï CÉLIA SOUZA VIEIRA

representa a epocha, o logar, o gosto do artista e as mais circunstancias do meio ambiente: e finalmente é um infinito relativo, como genero, por estar ligado a uma infinidão no meio das infinidades do universo[...]. A idea do nosso espirito, a estampa universal do bello em nós subjectivamente, subsiste sempre e compõe-se de tres elementos: o do ser, o da manifestação, e o da harmonia(SEIXAS, 1879, p. 152).

A obra de arte resulta da conciliação do finito com o infinito, do essencial com o acidental, da ideia com a forma, e, quer a sua criação, quer a sua recepção supõem a intervenção e a participação numa esfera superior, apelidada, no primeiro caso, de sexto sentido ou influencia secreta, e, no segundo caso, maravilhoso mysterio, capaz de libertar a alma do que é pequeno para fazê-la vaguear ñas vastidões do infinitoò (SEIXAS, 1879, p. 155). Todo o vocabulário deste capítulo transporta a experiência artística para um domínio próximo da experiência mística, fazendo mesmo equivaler a contemplação artística a um estado de arroubo e de ñantegozo da belleza ethereaò, onde a alma ñquebrando as algemas do variavel, do transitorio, se abalança ao eterno para entrar em um paraizo de perfeição, para idealmente conhecer, que há no homem muito de divinoò, enfim para na ñsublime ascensão sentir, que o espírito não procede do que é sensível mas sim de um ser, que nos attrahe e pelo qual a nossa alma clama nas maravillosas ancias da belleza infindaò (SEIXAS, 1879, p. 156).

Malgrado este pendor para dirimir a feição científica do discurso argumentativo, em favor de uma exposição muito próxima de um catolicismo racional e, sobretudo, do krausismo, parece-nos que é, porém, nesse esteio de concórdia e de sincretismo sobre que se desenvolve a influência krausista, que José Maria da Cunha Seixas vai encontrar um ponto de síntese entre o idealismo e o realismo na arte. Reconhecendo, no capítulo XX da Galeria de Ciências Contemporâneas, a validade da teoria sensualista, fundada no gosto e no princípio de fruição estética, bem como das teorias que atribuem à arte os imperativos de perfeição moral (arte revolucionária) e de verossimilhança, abalança-se a fazer a equação da polêmica que envolve as escolas realista e idealista. Defende que ambas são verdadeiras no que afirmam, que ñUma deve auxiliar a outraò, que apenas são errôneas no que excluem: o ñealista pode cahir no defeito da vulgaridade, o idealista no da inverosimilhançaò, pelo que a arte ñão pode sacrificar exclusivamente nas aras de uma só destas escholasò(SEIXAS, 1879, p. 162). A obra de arte deve representar a existência atual e, ao mesmo tempo, ñir mais longe, caminhar com a luz da philosophia e iniciar os povos nas grandes verdadesò (SEIXAS, 1879, p. 162). A redutibilidade do realismo e do idealismo resulta, obviamente, da união artística 
entre eterno e variável, que já expusera, e, por consequência, do influxo combinado dos princípios tainianos (v.g. ñO caracter dos povos pode influir muitoò (SEIXAS, 1879, p. 162), ñA arte é influenciada pelo tempoò(SEIXAS, 1879, p. 162), ñAs epochas influem nas ideas: a arte marcha como marcha a humanidadeò (SEIXAS, 1879, p. 163), etc.), da arte revolucionária de Proudhon (ñ̃roudhon quer a arte social, evangelisadora, humanitaria, mirando ao fim da perfeição das sociedades. Esta teoria tem muito de verdadeiroò (SEIXAS, 1879, p. 160)), do harmonismo pantiteísta (ñ̃Cremos firmemente, que todos os factos obedecem ás tres leis ontologicas do nosso systema: achar a verdade é applicar essas tres leis aos factos levando-os de leis simplices a outras mais geraes até se topetar com os altos paramos, para os quaes tudo é inaccessivel a não ser o universal, o metaphysico e o ontologicoò(SEIXAS, 1879, p. 172)) e, além de tudo, de Platão e Kant.

Por isso, quando publica $O$ Pantitheismo na Arte, Cunha Seixas precisa que o verdadeiro realismo estaria não no acesso à aparência das coisas, mas na indagação da sua essência, o que se deveria chamar realismo na arte seria a ñnegação do realò(SEIXAS, 1883, p. XXVIII). ${ }^{3}$ Como o positivismo era em filosofia uma fase preliminar do conhecimento, o atual realismo não podia deixar de suspeitar a existência de uma outra realidade por detrás da realidade que descrevia:

Esse realismo brutal encastella-se nos motivos dos actos humanos, nas indicações da ideozyncrasia de cada um, nos habitos, nos temperamentos e nôutros similhantes elementos; mas, como elles são consequentes de alguma cousa anterior, existente ou na pessoa de que tratamos, ou nos paes ou na raça, e, como, de antecedente em antecedente, o espirito não pode parar, sempre é certo que há um elemento interno, fixo e primordial, reflexo da permanencia e da eternidade, isto é, do absoluto. Assim é certo, que a natureza humana se não explica só por essa parte brutal, que apenas é entrada e perystillo para uma visão mais augusta do verdadeiro sanctuario do templo. Fazer-se da arte philosophia e dêsta arte parece uma empreza temeraria. [...] A arte é exactamente a personificação da idea casada com o facto, isto é, a conjuncção harmonica do absoluto com a individualidade (SEIXAS, 1883, p. XXIX).

Incumbia, desse modo, à arte realista uma elevada missão, que não consistia seguramente num mero afundar-se ñno limo das miserias humanasò, mas em ñesforçar-se por

\footnotetext{
${ }^{3}$ Cf. ainda: ñA effectividade das cousas está no que é insito, no que se occulta e em quasi tudo o que se ignora. $\mathrm{O}$ real é a essencia, isto é, o que menos conhecemos, o que só ao longe miramos, quando a analyse da sciencia afugenta tudo o que os sentidos nos patenteiam, fazendo a sciencia transformar se a materia em forças e movimento ou só em forças./ esse chamado realismo toma como reaes as apparencias (...)̀̀ (SEIXAS, 1883, p. XXVIII).
} 
tomar na humanidade a lição dos factosò: assim, ñquando põe em toda a sua nudez as chagas sociaes, não diga, que nâllas está a nossa natureza: insurja-se contra o facto e amostre o ideal, levantando a mão a apontar para o porvir e não se deliciando em deprimir-nos, antes erigindo protestos para que a humanidade seja outraò (SEIXAS, 1883, p. XXX). A arte filosófica ou realista teria como objetivo fazer o leitor pensar, levá-lo a indagar a substância que se encontra por detrás da manifestação dos fatos e da sua evolução.

Os limites da pretensa literatura científica residiriam, pois, nos próprios limites da ciência. Por exemplo, a discussão científica e filosófica sobre o que precede ou move o átomo, instância última a que chegara a ciência, dando lugar às mais variadas tentativas de encontrar o estado pré-átomo, é transportada para o campo da discussão literária como prova da insuficiência do espírito científico no acesso a uma realidade, nesta vertente, a humana, muito resistente a explicações exclusivamente fisiológicas. Por isso, vê bem Cunha Seixas, ao declarar que ñesta questão [do realismo] não é só litteraria: é uma alta questão de scienciaò (SEIXAS, 1884, p. 44). Numa recensão ao volume Scenographias ou Contos Naturalistas, de Reis Dâmaso, defende que realismo e romantismo, são, em última instância, duas facetas da natureza humana, ambas legítimas, desde que a primeira não caia na porno litteratura e desde que a segunda não se abandone em ñphantasias ideaesò: é certo que a sociedade atual exigia a pintura da natureza humana ñem toda a sua verdadeò, mas o realismo não podia repelir por inverossímil ño vago e indeciso de sentimentosò, ñporque a natureza humana é muito complicada e é um orgão de innumeras cordas, que soffre todos os tons e todas as composições, ainda as mais phantasticasò (SEIXAS, 1884, p. 45). Nessa medida, rejeita no realismo tudo o que conduza a um acanhamento da dimensão incógnita e inexplicável que ainda preside à conduta do homem. Por isso, para Cunha Seixas, é ñdogmatismo o dizer-se, que a natureza humana só tem as aspirações de Werther, que se matou por se achar nồm mundo tão acanhado. É certo, todavia, que há realmente naturezas como a de Werther e como a de Chatterton e sempre inaccessiveis aos moldes da vida vulgarò (SEIXAS, 1884, p. 4647).Neste, como noutros aspectos, diverge da escola naturalista, ñda qual Zola não é o pontifice, sendo porém um dos chefes visiveisò.

Refutar o naturalismo ou o realismo passa, pois, mais uma vez, pela demonstração dos limites da filosofia positivista, no que diz respeito à explicação do homem por analogia com o mundo biológico. Como não é só o físico que explica o moral e como a alma é, sob o seu ponto de vista, una, estando ñoda em cada um dos seus actosò (SEIXAS, 1884, p. 98), 
parece-lhe que o realismo, na sua forma atual explica o ñhomem physiologicoò e não o ñhomem todoò. Como conclusão, a sua visão sobre o realismo resume-se aos seguintes pontos:

Que a these do realismo - estudo da naturesa humana - lhe dá um fim justo, sendo certo que essa idéa não é nova, antes tão velha como o mundo litterario e artistico:

Que os meios para esse estudo podem ser os physiologicos para nos darem alguns aspectos da natureza humana:

Que o realismo, se entende que os seus meios lhe dão o homem todo, se afunda em bases dogmaticas e contrarias á verdade:

Que sendo incompleto será erroneo, logo que queira declarar, que a sua theoria é geral e que nada mais há a exportar se na sciencia esthetica:

Que por tanto não póde ser o ideal do mundo esthetico e de uma sociedade culta (SEIXAS, 1884, p. 100-101).

\section{Conclusão}

Na Península Ibérica, a formulação de programas literários realistas e naturalistas é precedida pela recepção de textos filosóficos que marcaram a peculiaridade da mentalidade e cultura dos últimos decênios dos Oitocentos.Ao refletir sobre o modo como alguns dos intelectuais conotados com círculos krausistas ou formados nas leituras de Proudhon e de Taine reagiram à afirmação do naturalismo, já na década de 80,observa-se um consenso quanto ao reconhecimento da importância de um programa estético de cunho mimético, socialmente empenhado e onde os critérios de verdade, objetividade e atualidade resultam da evidência de que qualquer reforma, em qualquer área do conhecimento, só encontraria chancela de validade e de credibilidade na proximidade com o pensamento filosófico-positivo que dominava o século. Mas observa-se também um desejo, para muitos dos intelectuais envolvidos na polêmica naturalista e antinaturalista ibérica, de encontrar uma forma de articulação entre o pensamento idealista/humanista e o cientificismo dominante, num espaço sociocultural e religioso minado por uma clivagem entre o antigo e o moderno, e onde o pensamento positivo, de que o naturalismo era herdeiro, desprovido de uma base de aceitação social ou de investimento científico real, encontrava dificuldades acrescidas para se infiltrar. É neste ambiente ibérico de crescente simpatia por um positivismo moderado (VIEIRA, 2004), que não exclua uma dimensão idealista e humanista, que os textos de teoria e de crítica literária de Cunha Seixas se inscrevem, ocupando uma posição distinta pela profundidade e amplitude dos conhecimentos filosóficos do autor. Nesta medida, Cunha Seixas, mesmo ao 
assumir a sua divergência relativamente a Krause, aproxima-se muito mais dos pensadores e críticos literários espanhóis que, como Manuel de la Revilla, Hermenegildo Giner, Urbano González Serrano, Leopoldo Alas, laboraram no esforço de afirmação de um krausismo positivista ou krausopositivismo, numa postura em que, acima da discussão literária, avulta um nítido interesse pelos pressupostos filosóficos e psicológicos na definição do ser humano considerado como um ñomem todoò.

\section{Referências}

BORGES, Paulo Alexandre Esteves.Deus e Criação em Cunha Seixas.Revista Portuguesa de Filosofia, tomo LI, n. 3-4, Braga, 1995, p. 427-460.

BRITO, Ferreira de. A Renascença e a Escola do Porto. Separata do Boletim Municipal de Cultura de Penafiel. Penafiel: Câmara Municipal, 1982.

.A Escola do Porto e Victor Hugo (O Grupo de A Grinalda). In:Actas do Colóquio Victor Hugo e Portugal.Porto: Faculdade de Letras do Porto, 1987, p.91-120.

GOMES, Pinharanda. Escola Portuense: uma introdução histórico-filosófica. In:Actas do Congresso Internacional Pensadores Portuenses Contemporâneo, 1850-1950. Lisboa: Universidade Católica Portuguesa; Imprensa Nacional-Casa da Moeda, v. I, 2002.

Dicionário de Filosofia. Lisboa: Dom Quixote, 2002.

GOMES, Pinharanda (Org.); CARVALHO, César Luís (Coord.). Cunha Seixas: uma filosofia de modernidade: antologia de estudos. São João Pesqueira: Câmara Municipal, 2006.

QUENTAL, Antero de. Tendencias Geraes da Philosophia na Segunda Metade do Seculo XIX. Revista de Portugal, n. 7, Porto, Lugan e Genelioux, Janeiro, 1890.

RIBEIRO, Álvaro. Cunha Seixas e a filosofia portuguesa. Separata. Revista Brasileira de Filosofia, vol. IX, fasc. II, abril-junho, São Paulo, Instituto Brasileiro de Filosofia, 1959.

SEIXAS, Cunha, J. M.A Phenix ou a Immortalidade da Alma Humana. Lisboa: C. Busch, 1870.

. Princípios Gerais da Filosofia da História. Lisboa: Typ. da Casa Progresso,1878, 2. ed. aumentada, 1897.

Galeria de Sciencias Contemporaneas. Porto: Imprensa Commercial de Santos Corrêa \& Mathias, 1879.

O Pantitheismo da Arte: cantos e poesias.Lisboa: Typ da Biblioteca Universal, 1883. 
. Ensaios de critica philosophica ou exposição do estado actual da philosophia. Lisboa: Typ. da Bibliotheca Universal, 1883.

Estudos de Literatura e de Filosofiasegundo o systema pantitheista.Lisboa: Typographia da Bibliotheca Universal, 1884.

TEIXEIRA, António Braz (1995). O pantiteísmo de Cunha Seixas.Revista Portuguesa de Filosofia, tomo LI, n. 3-4, Braga, p. 461-486.

VIEIRA, Célia. Teoria do romance naturalista ibérico e sua orientação francesa. Porto: Faculdade de Letras da Universidade do Porto. Dissertação de Doutoramento, 2004.

\title{
José Maria da Cunha Seixas (1836-1895), philosopher and literary critic
}

\begin{abstract}
In Portugal, one of the least studied intellectuals, from the point of view of literary criticism, in the difficult conciliation between the tradition of an idealistic mentality and the emergence of positivist thinking, is José Maria da Cunha Seixas (1836-1895), a philosopher and lawyer who was distinguished throughout the various essay volumes published in the 1870s and 1880s, not exactly by a peremptory refutation of Positivism, although its itinerary of reflection was associated with anti-materialist struggle, but by an attempt to harmonize its principles with the idealist German currents, namely with the Krausisme, of which its philosophical system drift and diverge. In this article, we will try to synthesize his perspective, in the context of the wide debate of the Portuguese naturalist and anti-naturalist literary criticism, using as sources of research the poetical and philosophical works of the author deposited in the bibliographic funds of the National Library of Portugal, Public Municipal of Porto and the Library of the Faculty of Letters of the University of Porto.
\end{abstract}

Keywords: CunhaSeixas.Naturalism. Pantitheism. Literary criticism. Literature.

Recebido em: 28 de agosto de 2017.

Aprovado em: 07 de outubro de 2017. 